\title{
Incidence and causes of tenosynovitis of the wrist extensors in long distance paddle canoeists
}

\author{
Paul du Toit, Gisela Sole, Pat Bowerbank, Timothy D Noakes
}

\begin{abstract}
Objectives-To investigate the incidence and causes of acute tenosynovitis of the forearm of long distance canoeists.

Method-A systematic sample of canoeists competing in four canoe marathons were interviewed. The interview included questions about the presence and severity of pain in the forearm and average training distances. Features of the paddles and canoes were determined.

Results-An average of $23 \%$ of the competitors in each race developed this condition. The incidence was significantly higher in the dominant than the nondominant hand but was unrelated to the type of canoe and the angle of the paddle blades. Canoeists who covered more than $100 \mathrm{~km}$ a week for eight weeks preceding the race had a significantly lower incidence of tenosynovitis than those who trained less. Environmental conditions during racing, including fast flowing water, high winds, and choppy waters, and the paddling techniques, especially hyperextension of the wrist during the pushing phase of the stroke, were both related to the incidence of tenosynovitis.

Conclusion-Tenosynovitis is a common injury in long distance canoeists. The study suggests that development of tenosynovitis is not related to the equipment used, but is probably caused by difficult paddling conditions, in particular uneven surface conditions, which may cause an altered paddling style. However, a number of factors can affect canoeing style. Level of fitness and the ability to balance even a less stable canoe, thereby maintaining optimum paddling style without repeated eccentric loading of the forearm tendons to limit hyperextension of the wrist, would seem to be important.

(Br F Sports Med 1999;33:105-109)
\end{abstract}

Keywords: tenosynovitis; tendon; wrist; forearm; canoeing

Unit, Sports Science

Institute of South

Africa, Newlands 7700,

South Africa

T D Noakes

Correspondence to: Professor T D Noakes, MRC/UCT Bioenergetics of Exercise Research Unit, Sports Science Institute of South Africa, Newlands 7700 , South Africa.

Accepted for publication 18 November 1998 either the wrist flexors or extensors of both hands, and is associated with a flexed or
Long distance canoeists, ${ }^{1}$ cane cutters, ${ }^{2}$ rowers, and racquet sports athletes ${ }^{3}$ suffer from acute tenosynovitis in the extensor tendons of the distal forearm. The injury is believed to result from excessive repetitive wrist movements. Tenosynovitis caused by cane cutting occurs in the flexor tendons of the forearm on the side that grips the cane and not the arm that wields the knife. In canoeists, the injury occurs in extended wrist respectively during the pull phase of the stroke. ${ }^{1}$ The wrist extensor injury in paddlers has been compared with the tendinitis found in weight lifters who do frequent curls. ${ }^{4}$ Athletes with the injury present with pain, which can be elicited by repeated wrist extension performed with a closed fist. Fusiform swelling may be present proximal to the wrist on the radial aspect of the dorsal forearm. ${ }^{3}$

Neither the causes nor incidence of the condition in different sports have been documented. Accordingly a study was conducted to establish the incidence of acute forearm extensor tendon tenosynovitis in long distance canoeists in South Africa. Water surface conditions differed in some of the races studied. This allowed the influence of environmental conditions on the incidence of the injury to be studied.

\section{Method}

POPULATION

Five hundred and ten canoeists were interviewed at four major long distance canoe events. These four events were chosen for their diversity in terms of weather, water conditions, water temperature, and the total distance covered. The four canoe marathons used were the $228 \mathrm{~km}$ Berg River canoe marathon, the 92 $\mathrm{km}$ Breede River canoe marathon, the $224 \mathrm{~km}$ Port Elizabeth to East London surf-ski challenge, and the $120 \mathrm{~km}$ Duzi canoe marathon.

BERG RIVER CANOE MARATHON

This event is contested in mid-winter and conditions can be extreme, with competitors facing strong winds, heavy rain, near freezing conditions, and cold water. Owing to these extreme weather conditions, the race is limited to a strictly selected field of 350 experienced canoeists who compete in single canoes. It is

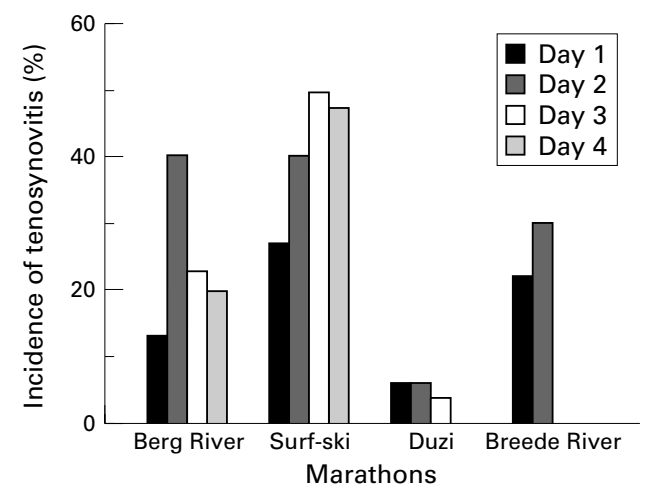

Figure 1 Incidence of tenosynovitis at the end of each day of the marathons. 


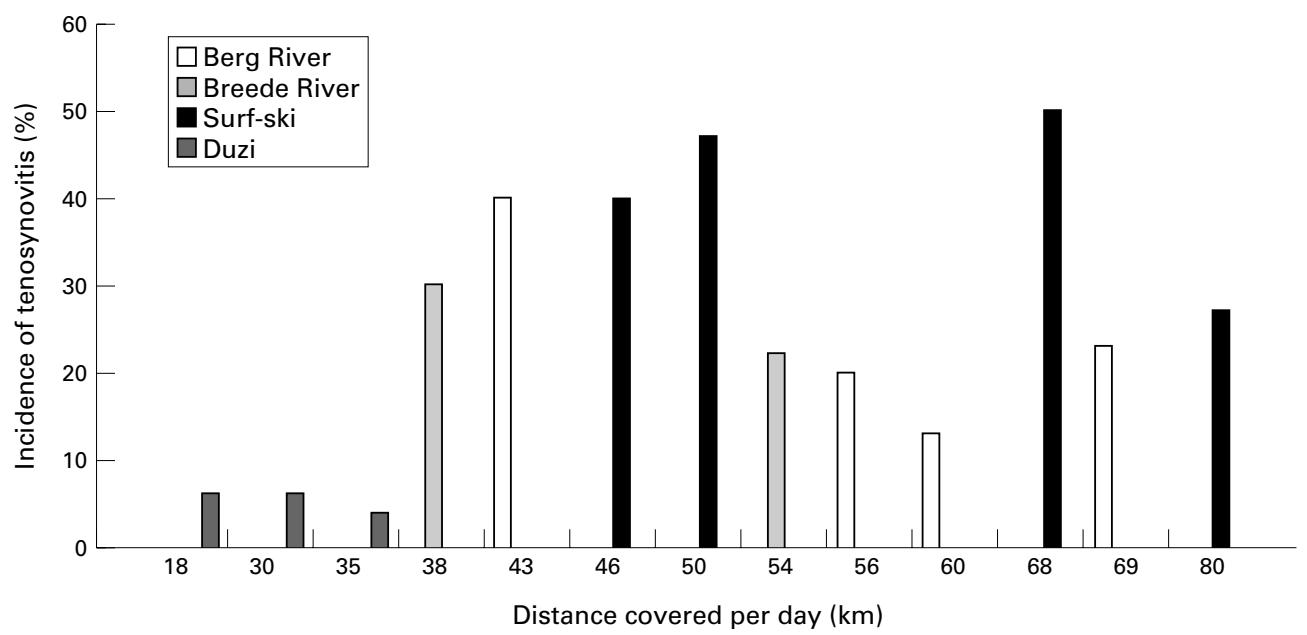

Figure 2 Incidence of tenosynovitis versus distance covered per day.

contested on four consecutive days over the daily distances of $60,43,69$, and $56 \mathrm{~km}$.

BREEDE RIVER CANOE MARATHON

This two day doubles event is held in early spring, covering daily distances of 54 and 38 $\mathrm{km}$ respectively.

\section{PORT ELIZABETH TO EAST LONDON SURF-SKI CHALLENGE}

This $244 \mathrm{~km}$ surf-ski marathon is an open sea event contested biannually in four stages in the Indian Ocean off South Africa. ${ }^{3}$ The event has two separate categories for singles and doubles skis. The consecutive daily paddling distances are $80,46,68$, and $50 \mathrm{~km}$.

\section{DUZI CANOE MARATHON}

This event comprises both river canoeing and running. On the first day, athletes paddle 18 $\mathrm{km}$ and run $18 \mathrm{~km}$; on the second day they paddle $30 \mathrm{~km}$ and run $8 \mathrm{~km}$; on the third and final day they paddle $36 \mathrm{~km}$ and run $10 \mathrm{~km}$.

SAMPLING METHOD

A systematic sample of the finishers of each day of the four canoe marathons was undertaken.

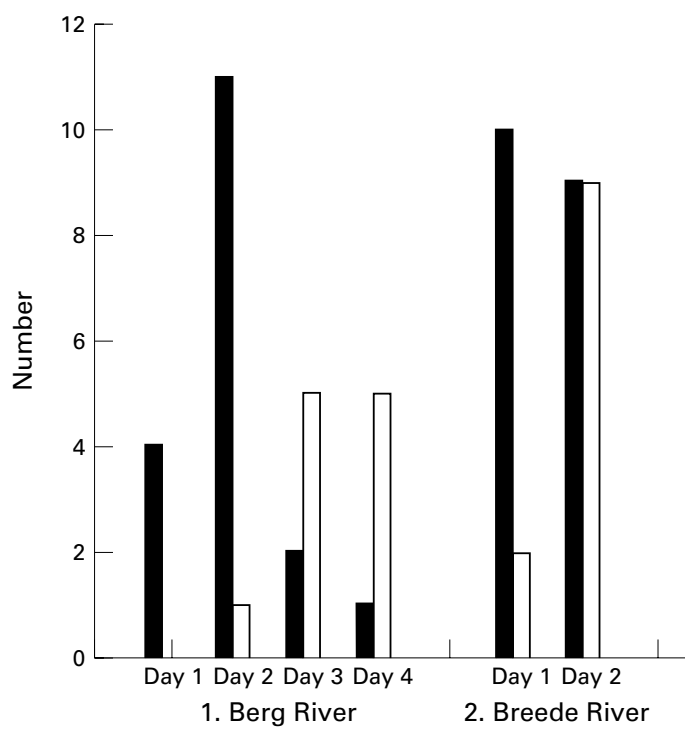

Some $10 \%$ of the finishers were interviewed each day. Because of television coverage of the top few paddlers, the tenth canoeist home each day was always the first to be interviewed and examined. Thereafter every tenth finisher was interviewed at the finish of each race on each day. Logistical problems and insufficient research staff meant that canoeists who did not complete the race for whatever reason could not be studied. Therefore we have measured the incidence of tenosynovitis in race finishers, not in the total racing population, which was a mixed sex population.

The interview and examination determined the following: hand dominance when paddling and the presence and severity of pain in the forearm tendons. In addition, the average weekly paddling distance during training in the eight weeks preceding the Berg River marathon was determined for the competitors in that race who were interviewed. The subjects were grouped into three categories on the basis of their training volume: those who trained less than $50 \mathrm{~km} /$ week, those who trained between 51 and $100 \mathrm{~km} /$ week, and those who trained more than $100 \mathrm{~km} /$ week.

Figure 3 Severity of tenosynovitis. 
Table 1 Causative factors for tenosynovitis in canoeists

\begin{tabular}{|c|c|c|c|}
\hline & $\begin{array}{l}\text { Injured } \\
\text { population }\end{array}$ & $n$ & Percentage \\
\hline \multicolumn{4}{|l|}{ Single canoes $(\mathrm{K} 1)$} \\
\hline \multicolumn{4}{|l|}{ Site of tenosynovitis } \\
\hline Dominant hand & 20 & 29 & $69^{\star}$ \\
\hline Opposite hand & 7 & 29 & 24 \\
\hline Both hands & 2 & 29 & 7 \\
\hline \multicolumn{4}{|c|}{ Weekly training distance } \\
\hline $0-50 \mathrm{~km}$ & 10 & 29 & $34^{\star \star}$ \\
\hline $50-100 \mathrm{~km}$ & 14 & 29 & $48^{\star \star}$ \\
\hline $101 \mathrm{~km}$ and over & 5 & 29 & $17^{\star \star}$ \\
\hline \multicolumn{4}{|c|}{ Angle between the paddle blades } \\
\hline $85^{\circ}$ backward & 21 & 84 & 25 \\
\hline $80^{\circ}$ backward & 3 & 9 & 33 \\
\hline $90^{\circ}$ backward & 4 & 15 & 26 \\
\hline $85^{\circ}$ forward & 1 & 11 & 9 \\
\hline \multicolumn{4}{|l|}{ Stability of canoe } \\
\hline Stable & 3 & 6 & 50 \\
\hline Intermediate & 5 & 17 & 29 \\
\hline Unstable & 21 & 97 & 22 \\
\hline \multicolumn{4}{|c|}{ Double canoes (K2 or double surf-ski) } \\
\hline \multicolumn{4}{|c|}{$\begin{array}{l}\text { Incidence of tenosynovitis from front and rear cockpit } \\
\text { of a K2 }\end{array}$} \\
\hline Front cockpit & 15 & 31 & 48 \\
\hline Rear cockpit & 16 & 31 & 52 \\
\hline \multicolumn{4}{|c|}{ Position of paddler in double surf-ski } \\
\hline Front cockpit & 19 & 35 & 54 \\
\hline Rear cockpit & 16 & 35 & 46 \\
\hline \multicolumn{4}{|l|}{ Stability of canoe } \\
\hline Stable & 5 & 24 & 21 \\
\hline Intermediate & 18 & 68 & 26 \\
\hline Unstable & 8 & 28 & 29 \\
\hline
\end{tabular}

${ }^{\star} \mathrm{p}<0.0001,{ }^{\star \star} \mathrm{p}<0.05\left(\chi^{2}\right.$ analysis $)$.

The severity of pain was graded according to the following scale: grade 1 , pain on full active wrist flexion and extension; grade 2 , local tenderness and swelling over the affected tendons on active flexion and extension; grade 3, local tenderness, swelling, and crepitus over the affected tendons and limited range of movement of wrist flexion and extension.

The paddle of each subject was then examined to determine the angle between the paddle blades and the feather of the blade. The circumference of the paddle shaft was measured with a tape measure and the material from which the paddle was manufactured was determined. It was not possible to assess the paddling techniques of the individual paddlers as this would have required a sophisticated laboratory analysis.

Finally, P d T, an experienced competitive canoeist, then classified each canoe into one of three groups according to its stability in the water: stable, intermediate, and unstable. This was a subjective analysis. To our knowledge, no simple and objective measure of canoe stability is currently available.

STATISTICAL METHODS

$\chi^{2}$ Tests were used to determine the relation between the incidence of pain and hand dominance and training distance. Fisher's test was used to determine the relation of incidence of pain and the angle between the paddle blades,

Table 2 Comparison of daily incidence (\%) of tenosynovitis in canoeists paddling in single or double surf-skis during the four day surf-ski challenge

\begin{tabular}{llllll}
\hline & Day 1 & Day 2 & Day 3 & Day 4 & Average \\
\hline Single surf-ski & 20 & 30 & 30 & 50 & 33 \\
Double surf-ski & 30 & 45 & 60 & 45 & 45 \\
\hline
\end{tabular}

Fisher's test: no significant difference. the stability of the canoes, and, where appropriate, the affected canoeist's seating position in the double canoes.

\section{Results}

Of 510 canoeists approached to participate in the study, only one refused. A total of 30 canoeists were examined at the end of each day in the Berg River and the Port Elizabeth to East London surf-ski marathons, 50 at the end of each day of the Duzi canoe marathon, and 60 after each of the two days of the Breede River marathon.

Figure 1 shows the incidence of tenosynovitis at the end of each day of the four canoe marathons. The incidence of tenosynovitis was much lower in the Duzi canoe marathon than in the other three races, and was least on the third day of that race. In contrast, in the three other races, the incidence of tenosynovitis was least on the first day of the race and increased on one or more of the subsequent days. High incidences of tenosynovitis $(>40 \%)$ were recorded on the second day of the Berg River marathon and on the last three days of the surf-ski marathon. The highest incidence $(50 \%)$ was recorded on the third day of the surf-ski marathon, the second longest leg of that event.

Figure 2 shows the incidence of tenosynovitis against distance paddled on each day. The incidence is low in events of less than $38 \mathrm{~km}$. Because of the compounding effect of the stage of the race (fig 1), there is no direct relation between distance paddled and the incidence of tenosynovitis.

Figure 3 shows the severity of tenosynovitis on the different days of the different races. During the Berg River canoe marathon, the incidence of grade 1 tenosynovitis was greatest on the second day. However, the incidence of grade 2 tenosynovitis increased from the second to the fourth day. The same general pattern was observed in the Breede River and surf-ski marathons. The only cases of grade 3 tenosynovitis were reported on the third and fourth days of the surf-ski marathon. During the Duzi canoe marathon, only grade 1 tenosynovitis was reported, in keeping with the generally lower incidence of tenosynovitis in that race (fig 1).

The contribution of specific aetiological variables to the probability of developing tenosynovitis was studied in single (K1) competitors in the Berg River canoe marathon and in paddlers in double canoes, either $\mathrm{K} 2$ or double surf-skis (table 1 ).

The four day surf-ski marathon produced the highest frequency of tenosynovitis (fig 1). Competitors in double surf-skis generally had a higher incidence of tenosynovitis than did those paddling in single skis during that race (table 2).

In single canoeists, the incidence of tenosynovitis was significantly higher in the dominant hand in those who paddled less than 100 $\mathrm{km}$ a week (table 1). The angle between the paddle blades and the stability of the canoe were not significantly related to injury risk, although paddlers in stable canoes had a high rate of injury. No significant difference was found between the rates of injury of canoeists 
using stable versus unstable and intermediate canoes. In canoeists paddling in double canoes, neither the position in the boat nor the stability of the canoe was associated with injury risk (table 1).

\section{Discussion}

Of the 510 canoeists interviewed at the four canoe marathons, 117 (23\%) suffered from tenosynovitis. Hence this condition is perhaps more common than is currently appreciated. A number of factors were associated with a higher probability of developing the injury. Firstly, the incidence of tenosynovitis was always lowest on the first day of each event (fig 1). Thus the probability of injury rose when there had been a previous bout of exercise. Secondly, injury incidence was greater in stages longer than 38 $\mathrm{km}$ (fig 2) especially if there had been at least one previous bout of paddling.

Thirdly, and perhaps more importantly, there appears to be a major influence of water surface conditions on the risk of injury. For example, the high incidence of tenosynovitis on the second (shortest) stage of the Berg River canoe marathon (fig 1) was double that at the end of the fourth (final) day. The section of river covered on the first two days is fast flowing with a number of small rapids and many whirlpools. Thereafter it gradually becomes wider and slower as it approaches its termination in the Atlantic Ocean.

Similarly, the incidence of tenosynovitis in the surf-ski marathon was, on average, much higher than any of the other three events (fig 1). The fact that this event takes place on the unprotected sea where surface conditions are usually much rougher than on rivers probably explains this phenomenon. On the first two days of the race studied, the sea was calm and there was no wind. However, on the third day, a 15 knot wind was blowing and the sea was very choppy. By the fourth day the wind had picked up to gale force, the sea was very choppy, and there were high swells. The incidence of tenosynovitis on these last two days was the highest recorded in any event (fig 1). Furthermore, only on those two days (fig 3 ) were cases of grade 3 tenosynovitis reported, with the highest incidence on the fourth day.

The Umsinduzi River on which the Duzi canoe marathon is held was extremely low at the time of study. The river was flowing slowly with few rapids and very little turbulence. These factors increase the amount of running and reduce the amount of canoeing of each competitor. The incidence of tenosynovitis was much lower than in any of the other events studied (fig 1), and only grade 1 tenosynovitis was diagnosed (fig 3). The combination of canoeing and running also contributes to the low incidence of tenosynovitis, as the arms are rested during the running stages.

Fourthly, significantly more canoeists $(69 \%)$ suffered from tenosynovitis in their dominant hand (table 1). To appreciate the possible relevance of this finding, it is necessary to understand the correct canoeing technique. Most of the power in canoeing comes from the opposite hand pushing the boat past the blade in the water. The hand on the side of the blade in the water acts as a guide to ensure that the blade travels perpendicularly to the canoe. The important technique is that the wrist of the pushing arm should not be extended during the pushing phase of the stroke. To minimise wind resistance on the pushing blade during the stroke, the paddle blades are angled at about $90^{\circ}$ to each other. When the shaft is swivelled through the $90^{\circ}$ rotation that occurs twice for each paddle stroke, the dominant hand grips the paddle while the other hand allows the shaft to rotate.

We postulate that the dominant hand will be more likely to develop tenosynovitis if it is forced to contract eccentrically to limit hyperextension when paddling on rough waters. This would occur if the shaft of the paddle is gripped too tightly by the non-dominant hand. As a result, the blade will not swivel normally, and the dominant hand will be forced into hyperextension so that the full $90^{\circ}$ rotation occurs allowing the opposite blade to enter the water perpendicularly to the canoe. Thus we postulate that poor water conditions promote tenosynovitis by forcing canoeists to grasp the paddle with the non-dominant hand in an attempt to maintain balance.

Paradoxically, the incidence of injury was greatest in canoeists paddling in single stable canoes (table 1), although this difference was not statistically significant. This can be explained by the fact that inexperienced canoeists use such canoes. These paddlers are less able to maintain balance even in their more stable canoes.

Finally, we found that canoeists who paddled over $100 \mathrm{~km}$ a week in the eight weeks preceding the event had a significantly lower incidence of tenosynovitis than those who did less training. There are three possible explanations for this. Firstly, the training had adapted their forearm muscles and tendons better to accommodate the load of repetitive days of canoeing. In addition, the fitter the canoeists, the longer they should be able to maintain the ideal canoeing style. It is possibe that fatigue or loss of concentration causes loss of style which predisposes to tenosynovitis. Alternatively, canoeists able to train $100 \mathrm{~km}$ a week or more may be a self selected group at low risk of this injury because of unique genetic, biomechanical, or other factors.

In conclusion, this study clearly shows that tenosynovitis is a common injury in long distance canoeists. The study also suggests that the cause is not related to the equipment used, but is probably to do with difficult paddling conditions, in particular uneven surface conditions, which cause altered paddling style. However, a number of factors can affect canoeing style. Level of fitness and the ability to balance even a less stable canoe, thereby maintaining optimum paddling style without repeated eccentric loading of the forearm tendons to limit hyperextension of the wrist, would seem to be important.

This study was completed by $\mathrm{P} \mathrm{d} \mathrm{T}$ in partial fulfilment of the degree BSc (Physiotherapy) in the Department of Physi- 
otherapy of the University of Cape Town Medical School. This research was financially supported by Smith and Nephew and Plascon Paints.

1 Walsh M. Preventing injury in competitive canoeists. Physician and Sportsmedicine 1985;13:120-8.
2 Clarke WB, Lanfear RT. The treatment of tenosynovitis in industry. Physiotherapy 1972;23:120-4.

3 Tully E, Abbot J. The wrist and hand. In: Zuluaga M, Briggs C, Carlisle J, et al, eds. Sports physiotherapy: applied science and practise. Edinburgh: Churchill Livingstone, 1995:454-5.

4 Burrell CL, Burrell R. Injuries in Whitewater paddling. Physician and Sportsmedicine 1982;10:119-24.

\section{Take home message}

Tenosynovitis of the forearm sensors is a common injury in long distance canoeists. The cause does not seem to be related to the equipment that is used, but is probably caused by difficult paddling conditions - in particular, uneven surface conditions that may cause an altered paddling style

\section{A fable: a journey through evidence based medicine by the ancient mariner}

Once upon a time a large Island called Gnorance lay surrounded by a wondrous land call No Ledge. Though on some sides the sea had been charted in the Great Book of Myths, vast areas were covered in great swirling Mists of Confusion. Adventurers had reached No Ledge but against their will had always been returned by the Mountain of Questions to Gnorance. Many Searchers, as they were known, would sail the Mists of Confusion and would record their wanderings in the Great Book of Myths. Not all the Searchers wrote well, so a wise man, the Head Searcher, or in the East End of Gnorance, the 'Ead, was appointed. Some Searchers received vast funds and sailed through the Mists in large well equipped boats, but even these boats did not always gain access to No ledge. Some Visionaries never even set sail but would believe their visions and submit them as facts to the Great Book of Myths. So the 'Ead divided the Myths into original reports from the great ships who could record their navigation accurately, quasi or Quase Reports for those with not such good navigational aids, and the Let us Pray group or Let Us for short. The Searchers themselves would only trust "originals" even if the ship failed to reach No Ledge, whilst Quase reports and especially Let Us were considered of little value.

One year Gnorance suffered a great plague and many men, women, and children died, so the rulers, or Trusters, sent great ships to find No Ledge and the answers. The captains studied the Myths, at least the Searchers' originals, all to no avail. So in desperation they read the Quase reports and, may the great Myth forgive us, they even read the Let Us. Years passed and the plague continued unabated except in one village where F L Eming cured all who came to him. Many years before Eming had taken his small boat to No Ledge and returned with The Cure.

Why had Eming not reported his findings in the Great Book? Eming had submitted details of his journey and believing he had The Cure had submitted an original, for he had not fully understood the rules of the Book of Myths. Foolish man, navigation points were indeed there, but not checked from north, south, east, and west, and the 'Ead, who was busy accepting a Great Searcher's original that proved that No Ledge was not where it wasn't, had sent Eming a Three Liner. Now a Three Liner casts Visionaries back to their dreams and Eming had fled the city back to his village.

So now the Council of Searchers took The Cure themselves, followed Eming's navigation points, and checked them from north, south, east, and west, so that years later, long after the plague was defeated, they presented proof of The Cure.

What had gone wrong? Eming had found The Cure ten years before they proved that The Cure cured, but he had not understood the guide to the Rules of the Book of Myths that it was "an intellectual tradition" that the line of 'Eads followed. Searchers write long detailed originals, Quasies write of sightings, and Let Us write of thoughts. Though Eming's navigation points were accurate and he had in fact found The Cure, he had not the equipment to prove this and foolishly submitted his accurate report which the Searchers had judged as an original. He had not used Searcher speech, a language spoken on big Gnorance sailing ships, so had been sent the Three Liner.

What of the 'Ead who had only followed the line of 'Eads? He recalled the Great Major Domo 'Ead who received the Djen Ings first report. "A pox on you" he had thought but instead of the Three Liner he suggested Djen Ings rewrite his report as a shorter or Quase Report. Perhaps thought the 'Ead, I'll adjust the guide to the Rules of the Book of Myths to make them clearer and not reject an obvious Quase report after subjecting it to a Searchers' examination.

And everyone lived happily ever after! 